Pacific Journal of Mathematics

NNER-OUTER FACTORIZATION OF FUNCTIONS WHOA 


\section{INNER-OUTER FACTORIZATION OF FUNCTIONS WHOSE FOURIER SERIES VANISH OFF A SEMIGROUP}

\section{Howard Lewis PenN}

Let $G$ be a compact, connected, Abelian group. Its dual, $\Gamma$, is discrete and can be ordered. Let $\Gamma_{1}$ be a semigroup which is a subset of the positive elements for some ordering, but which contains the origin of $\Gamma$. Let $H^{p}\left(\Gamma_{1}\right)$ be the subspace of $L^{p}(G)$ consisting of functions which have vanishing off $\Gamma_{1}$. The question that this paper is concerned with is what conditions on a function in $H^{p}\left(\Gamma_{1}\right)$ assure an inner-outer factorization.

An inner function is a function $f \in H^{\infty}\left(\Gamma_{1}\right)$ such that $|f|=1$ a.e. $(d x)$ on $G$. A function $f \in H^{p}\left(\Gamma_{1}\right)$ is said to be outer if

$$
\int_{G} \log |f(x)|=\log \left|\int_{G} f(x) d x\right|>-\infty \text {. }
$$

A function $f \in H^{1}\left(\Gamma_{1}\right)$ is said to be in the class $L R P\left(\Gamma_{1}\right)$ if $\log |f| \in \Gamma_{1}(G)$ and $\log |f|$ has Fourier coefficients equal to zero off $\Gamma_{1} \cup-\Gamma_{1}$. The main result of the paper is that if $\Gamma_{1}$ is the intersection of half planes and $f \in H^{1}\left(\Gamma_{1}\right)$ with $\int_{G} \log |f(x)| d x>-\infty$ then $f$ has an inner-outer factorization if and only if $\log |f|$ is in $L R P\left(\Gamma_{1}\right)$.

A semigroup, $P$, in $\Gamma_{1}$ is called a half plane if $P \cup-P=\Gamma$ and $P \cap-P=\{0\}$. Helson and Lowdenslager [2] proved that if $\Gamma_{1}$ is a half plane then every function $f \in H^{p}\left(\Gamma_{1}\right)$ with $\int \log |f| d x>-\infty$ has a factorization as a product of an outer function, $h \in H^{p}\left(\Gamma_{1}\right)$ and an inner function, $g$, and this factorization is unique up to multiplication by constants of magnitude 1. From now on we shall assume $\int \log |f| d x>-\infty$.

Helson and Lowdenslager also showed [3] that if $u$ is a real function such that $u$ and $e^{u}$ are summable, and $v$ is the conjugate function of $u$ with respect to the half plane, $\Gamma_{1}$, then $e^{u+i v}$ is an outer function in $H^{1}\left(\Gamma_{1}\right)$. Conversely, if a summable outer function has the represention $e^{u+i v}$ with $u$ and $v$ real then $u$ is summable and $v$ is equal to its conjugate modulo $2 \pi$ except for an additive constant.

Let $P$ be a half plane which contains $\Gamma_{1}$. Then, for $u \in L_{R}^{1}(G)$ there exists a conjugate function, $v$, which is unique if we assume $v(0)=0$, such that $u+i v$ has its Fourier series supported on $P$. The function, $v$, is in $L^{p}, p<1$. If $u$ has its Fourier coefficients supported only on $\Gamma_{1} \cup-\Gamma_{1}$ then $u+i v$ has its Fourier coefficients supported only on $\Gamma_{1}$ [4, Chap. 8, §7]. Therefore, $f \in L R P\left(\Gamma_{1}\right)$ if 
and only if $\log |f| \in L^{1}$ and $\log |f|$ is the real part of a function whose Fourier coefficients vanish off $\Gamma_{1}$.

THEOREM. Assuming that $f \in H^{1}\left(\Gamma_{1}\right)$ and $\int \log |f| d x>-\infty$, and that $\Gamma_{i}=\bigcap_{i \in I} P_{i}$, then $f$ has an inner-outer factorization if and only if $\log |f|$ has its Fourier coefficients vanish off $\Gamma_{1} \cup-\Gamma_{1}$.

Proof. Assume $f \in L R P\left(\Gamma_{1}\right)$. Let $u=\log |f| \in L^{1}(G)$. Take any $i \in I$ and consider $P_{i} . \quad \Gamma_{1} \subset P_{i}$ and $f$ has an inner-outer factorization with respect to $P_{i}$. The outer factor is given by $e^{u+i v_{i}}$ where $v_{i}$ is the conjugate function to $u$ with respect to $P_{i}$. Since $u$ has its Fourier coefficients supported on $\Gamma_{1} \cup-\Gamma_{1}$, it follow that $v_{i}$ also has its Fourier coefficients supported there. Therefore, $v_{i}$ is the same as the conjugate function of $u$ with respect to any of the other half planes $P_{j}, j \in I$. Therefore, the outer factor of $f$ in $H^{1}\left(P_{i}\right)$ is given by $e^{u+i v_{i}}$. Also, if $P_{j}$ is any of the other half planes whose intersection gives $\Gamma_{1}$, then the outer factor $f$ in $H^{1}\left(P_{j}\right)$ is $e^{u+i v_{j}}$. Therefore, $e^{u+i v_{i}} \in \bigcap_{i \in I} H^{1}\left(P_{i}\right)$, which is just equal to $H^{1}\left(\Gamma_{1}\right)$. For each half plane $P_{i}, i \in I$, we have that the inner factor is given by $f e^{-\left(u+i v_{i}\right)}$. Therefore, the inner factor is also in $H^{1}\left(\Gamma_{1}\right)$.

Conversely, assume that $f$ has an inner-outer factorization, $g h$, in $H^{1}\left(\Gamma_{1}\right)$. Choose $P_{j}, j \in I$, then the outer factor, $h$, of $f$ in $H^{1}\left(\Gamma_{1}\right)$, and hence in $H^{1}\left(P_{j}\right)$, is given by $e^{u+v_{j}}$, where $v_{j}$ is the conjugate function of $u=\log |f|$ with respect to $P_{j}$. Since this is true for all $P_{j}, j \in I$, it follows that $e^{i v_{j}}$ is the same regardless of which half plane, $P_{j}$ is used. Now assume $P_{k}$ is another of the half planes whose intersection is $\Gamma_{1}$. Then $e^{i u_{k}}=e^{i u_{j}}$ where $v_{k}$ is the conjugate function of $u$ with respect to $P_{j}$. It follows that $v_{k}(x)=v_{j}(x)+2 n \pi$ where $n$ might change from point to point. We will now show that $n=0$. Consider the function $h^{1 / 2}$ which is outer in $H^{2}\left(\Gamma_{1}\right) \subset H^{1}\left(\Gamma_{1}\right)$. It follows that $\log \left|h^{1 / 2}\right|=u / 2$. The conjugate function of $u / 2$ with respect to $p_{j}$ is $v_{j} / 2$ and its conjugate function with respect to $P_{k}$ is $v_{k} / 2$. By the Helson and Lowdenslager theorem $h^{1 / 2}=e^{\left(u+i v_{j}\right) 2}$ and also $h^{1 / 2}=e^{\left(u+i v_{k}\right) / 2}$. Therefore,

$$
h=h^{1 / 2} h^{1 / 2}=e^{u+i\left(v_{j}+v_{k}\right) / 2} .
$$

Hence

$$
v_{k}(x)=\left(v_{j}(x)+v_{k}(x)\right) / 2+2 n \pi .
$$

So,

$$
v_{k}(x)=v_{j}(x)+4 n \pi .
$$

Now consider $h^{1 / 4}=e^{\left(u+i v_{j}\right) / 4}=e^{\left(u+i v_{k}\right) / 4}$. Therefore, 


$$
h=h^{3 / 4} h^{1 / 4}=e^{3\left(u+i v_{k}\right) / 4} e^{\left(u+i v_{j}\right) / 4}=e^{u+i\left(3 v_{k}+v_{j}\right) / 4} .
$$

Hence,

$$
v_{k}(x)=v_{j}(x)+8 n \pi .
$$

By considering the $2^{m}$ th roots of $h$ we can show that the difference between $v_{k}$ and $v_{j}$ must be $2^{m+1} n \pi$. This must hold for all values of $m$. The only integer for which this is true is 0 . Therefore $u$ has the same conjugate function with respect to each of the half planes.

We will show that $u$ has its Fourier coefficients supported of $\Gamma_{1} \cup-\Gamma_{1}$. Suppose that $\hat{u}(\gamma) \neq 0$, where $\gamma \notin \Gamma_{1} \cup-\Gamma_{1}$. Then there exists $P_{j}, j \in I$ such that $\gamma \notin P_{j}$. There also exists $P_{k}, k \in I$, such that $\gamma \notin-P_{k}$. Let $v_{j}$ be the conjugate functions of $u$ with respect to the half plane, $P_{j}$ and let $v_{k}$ be the conjugate function of $u$ with respect to $P_{k}$. Since $\gamma \notin P_{j}$, we have

$$
\hat{v}_{j}(\gamma)=i \widehat{u}(\gamma)
$$

[4, Chap. 8, §7]. Likewise, since $\gamma \notin-P_{k}$ it follows that $\gamma \in P_{k} \backslash 0$ and that

$$
\hat{v}_{k}(\gamma)=-i \hat{u}(\gamma)
$$

But since $\widehat{u}(\gamma) \neq 0$, we have $\hat{v}_{j}(\gamma) \neq \widehat{v}_{k}(\gamma)$, and hence $v_{j}$ and $v_{k}$ are different functions. But we have just shown that $u$ has the same conjugate function with respect to each half plane. Therefore $\hat{u}(\gamma)=0$ and $u$ has its Fourier series supported on $\Gamma_{1} \cup-\Gamma_{1}$. Therefore $f \in \operatorname{LRP}\left(\Gamma_{1}\right)$.

COROLLARY. If $f \in H^{1}\left(\Gamma_{1}\right)$ where $\Gamma_{1}$ is the intersection of half planes and $f \in \operatorname{LRP}\left(\Gamma_{1}\right)$, then $f=p_{1} p_{2}$ where $p_{1}, p_{2} \in H^{2}\left(\Gamma_{1}\right)$ and $\left|p_{1}\right|^{2} \equiv\left|p_{2}\right|^{2} \equiv|f|$

EXAMPLE. In [1] Ebenstein discusses the $H^{p}$ functions on a semigroup which is the intersection of a countable collection of half planes. This semigroup fulfills the hypothesis of the theorem. Let $T^{\omega}$ be the compact group which is the Cartesian product of countably many circles. The dual $\sum_{i=I}^{\infty} Z$, is the direct sum of countably many copies of the integers. Define $A \subset \sum_{i=1}^{\infty} Z$ by

$$
A=\left\{x: x_{i} \geqq 0 \text { for all } i\right\} \text {. }
$$

We may define $H^{p}\left(T^{\omega}\right), p \geqq 1$ as the subset of $L^{p}\left(T^{\omega}\right)$ consisting of these functions whose Fourier coefficients vanish off $A$. The semigroup, $A$, is the intersection of half planes $P_{i}$ defined as follows: 


$$
\begin{aligned}
P_{i}=\left\{x: x_{i} \geqq 0,\right. & \text { if } x_{i}=0 \text { then } x_{1} \geqq 0, \\
& \text { if } \left.x_{1}, x_{2}, \cdots, x_{j}=0 \text { then } x_{j+1}=0\right\} .
\end{aligned}
$$

Therefore the theorem applies to $H^{p}\left(T^{\omega}\right)$.

REMARK. One might hope that certain theorems which hold for the $H^{p}$ spaces of the disk would remain true, at least for the class $\operatorname{LRP}\left(\Gamma_{1}\right)$. One such theorem is Szego's theorem which states if $w \in L^{1}(d x)$ and $w \geqq 0$, then

$$
\inf _{g \in A_{0}} \int|1-g|^{2} w d x=\exp \int \log (w) d x
$$

where $A_{0}$ consists of those polynomials supported on $\Gamma_{1}$, with zero-th coefficient equal to zero. This theorem is true if $\Gamma_{1}$ is a half plane [4, Chap. 8, §3]. Rudin has an example [5, Theorem 4.4.8] of a function, $f$, which is outer, but does not span. This same function can be used to show that Szego's theorem fails even for the class $L R P$.

\section{REFERENCES}

1. Samuel E. Ebenstein, Some $H^{p}$ spaces which are uncomlimented in $L^{p}$, Pacific J. Math., 43 (1972), 327-339.

2. H. Helson and D. Lowdenslager, Prediction theory and Fourier analysis in several variables I, Acta. Math., 99 (1958), 105-202.

3. - Prediction theory and Fourier analysis in several variables II, Acta. Math., 106 (1961), 175-213.

4. Walter Rudin, Fourier Analysis on Groups, Interscience, New York, (1962).

5. - Function Theory in Polydiscs, Benjamin, New York, (1969).

Received November 19, 1974 and in revised form November 8, 1976. The work in this paper was completed as part of the author's doctorial thesis at the University of Michigan.

United States Naval ACademy

ANNAPOLIS, MD 21402 


\section{PACIFIC JOURNAL OF MATHEMATICS}

\section{EDITORS}

RICHARD ARENS (Managing Editor)

University of California

Los Angeles, CA 90024

R. A. BEAUMONT

University of Washington

Seattle, WA 98105

C. C. Moore

University of California

Berkeley, CA 94720

\section{J. DugundJI}

Department of Mathematics

University of Southern California

Los Angeles, CA 90007

R. Finn and J. Milgram

Stanford University

Stanford, CA 94305

\section{ASSOCIATE EDITORS}

\section{E. F. BECKENBACH}

B. H. NEUMANN

F. WoLF

K. YOSHIDA

\section{SUPPORTING INSTITUTIONS}

\author{
UNIVERSITY OF BRITISH COLUMBIA \\ CALIFORNIA INSTITUTE OF TECHNOLOGY \\ UNIVERSITY OF CALIFORNIA \\ MONTANA STATE UNIVERSITY \\ UNIVERSITY OF NEVADA \\ NEW MEXICO STATE UNIVERSITY \\ OREGON STATE UNIVERSITY \\ UNIVERSITY OF OREGON \\ OSAKA UNIVERSITY
}

\author{
UNIVERSITY OF SOUTHERN CALIFORNIA \\ STANFORD UNIVERSITY \\ UNIVERSITY OF HAWAII \\ UNIVERSITY OF TOKYO \\ UNIVERSITY OF UTAH \\ WASHINGTON STATE UNIVERSITY \\ UNIVERSITY OF WASHINGTON \\ AMERICAN MATHEMATICAL SOCIETY
}

The Supporting Institutions listed above contribute to the cost of publication of this Journal, but they are not owners or publishers and have no responsibility for its content or policies.

Mathematical papers intended for publication in the Pacific Jaurnal of Mathematics should be in typed form or offset-reproduced, (not dittoed), double spaced with large margins. Please do not use built up fractions in the text of your manuscript. You may however, use them in the displayed equations. Underline Greek letters in red, German in green, and script in blue. The first paragraph or two must be capable of being used separately as a synopsis of the entire paper. Items of the bibliography should not be cited there unless absolutely necessary, in which case they must be identified by author and Journal, rather than by item number. Manuscripts, in triplicate, may be sent to any one of the editors. Please classify according to the scheme of Math. Reviews, Index to Vol. 39. All other communications should be addressed to the managing editor, or Elaine Barth, University of California, Los Angeles, California, 90024.

The Pacific Journal of Mathematics expects the author's institution to pay page charges, and reserves the right to delay publication for nonpayment of charges in case of financial emergency

100 reprints are provided free for each article, only if page charges have been substantially paid. Additional copies may be obtained at cost in multiples of 50 .

The Pacific Journal of Mathematics is issued monthly as of January 1966. Regular subscription rate: $\$ 7200$ a year (6 Vols., 12 issues). Special rate: $\$ 36.00$ a year to individual members of supporting institutions.

Subscriptions, orders for back numbers, and changes of address should be sent to Pacific Journal of Mathematics, 103 Highland Boulevard, Berkeley, California, 94708.

PUBLISHED BY PACIFIC JOURNAL OF MATHEMATICS, A NON-PROFIT CORPORATION

Printed at Kokusai Bunken Insatsusha (International Academic Printing Co., Ltd.). 8-8, 3-chome, Takadanobaba, Shinjuku-ku, Tokyo 160, Japan.

Copyrit (C) 1975 by Pacific Journal of Mathematics Manufactured and first issued in Japan 


\section{Pacific Journal of Mathematics \\ Vol. 69, No. $2 \quad$ June, 1977}

Carol Alf and Thomas Alfonso O'Connor, Unimodality of the Lévy spectral

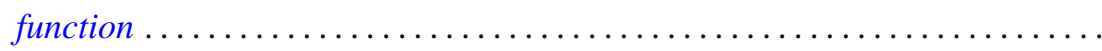

S. J. Bernau and Howard E. Lacey, Bicontractive projections and reordering of

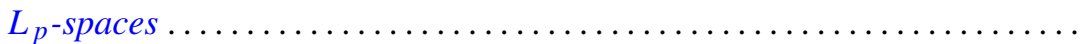

Andrew J. Berner, Products of compact spaces with bi-k and related spaces..... 303

Stephen Richard Bernfeld, The extendability and uniqueness of solutions of ordinary differential equations ...............................

Marilyn Breen, Decompositions for nonclosed planar m-convex sets ..........

Robert F. Brown, Cohomology of homomorphisms of Lie algebras and Lie

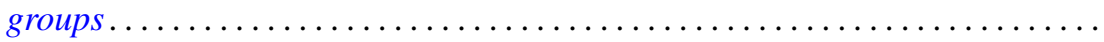

Jack Douglas Bryant and Thomas Francis McCabe, A note on Edelstein's iterative test and spaces of continuous functions ....................

Victor P. Camillo, Modules whose quotients have finite Goldie dimension ....... 333

David Downing and William A. Kirk, A generalization of Caristi's theorem with

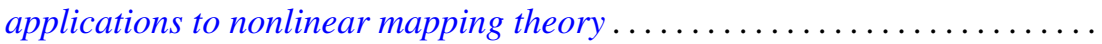

Daniel Reuven Farkas and Robert L. Snider, Noetherian fixed rings ...........

Alessandro Figà-Talamanca, Positive definite functions which vanish at

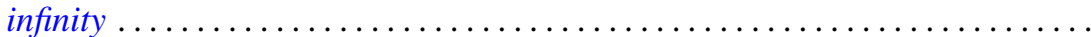

Josip Globevnik, The range of analytic extensions .................. 365

André Goldman, Mesures cylindriques, mesures vectorielles et questions de

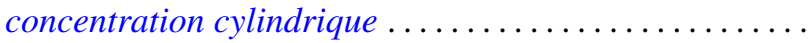

Richard Grassl, Multisectioned partitions of integers..........

Haruo Kitahara and Shinsuke Yorozu, A formula for the normal part of the

Laplace-Beltrami operator on the foliated manifold .... .

Marvin J. Kohn, Summability $R_{r}$ for double series .........

Charles Philip Lanski, Lie ideals and derivations in rings with involution ..

Solomon Leader, A topological characterization of Banach contractions . .

Daniel Francis Xavier O’Reilly, Cobordism classes of fiber bundles . .

James William Pendergrass, The Schur subgroup of the Brauer group . .

Howard Lewis Penn, Inner-outer factorization of functions whose Fourier series

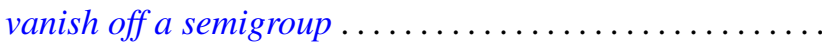

501

William T. Reid, Some results on the Floquet theory for disconjugate definite

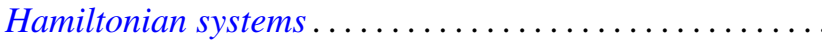

Caroll Vernon Riecke, Complementation in the lattice of convergence

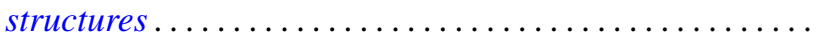

Louis Halle Rowen, Classes of rings torsion-free over their centers ......... 527

Manda Butchi Suryanarayana, A Sobolev space and a Darboux problem ....... 535

Charles Thomas Tucker, II, Riesz homomorphisms and positive linear maps.... 551

William W. Williams, Semigroups with identity on Peano continua ........... 557

Yukinobu Yajima, On spaces which have a closure-preserving cover by finite 